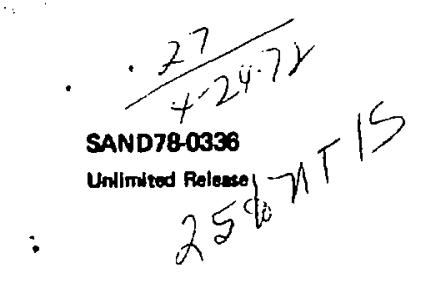

\title{
The Thomson Parabola Ion Analyzer
}

Michad A. Gusinow, Maurice M. Dillon, Grent L Lockwood, Leurence E. Rugntes

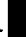

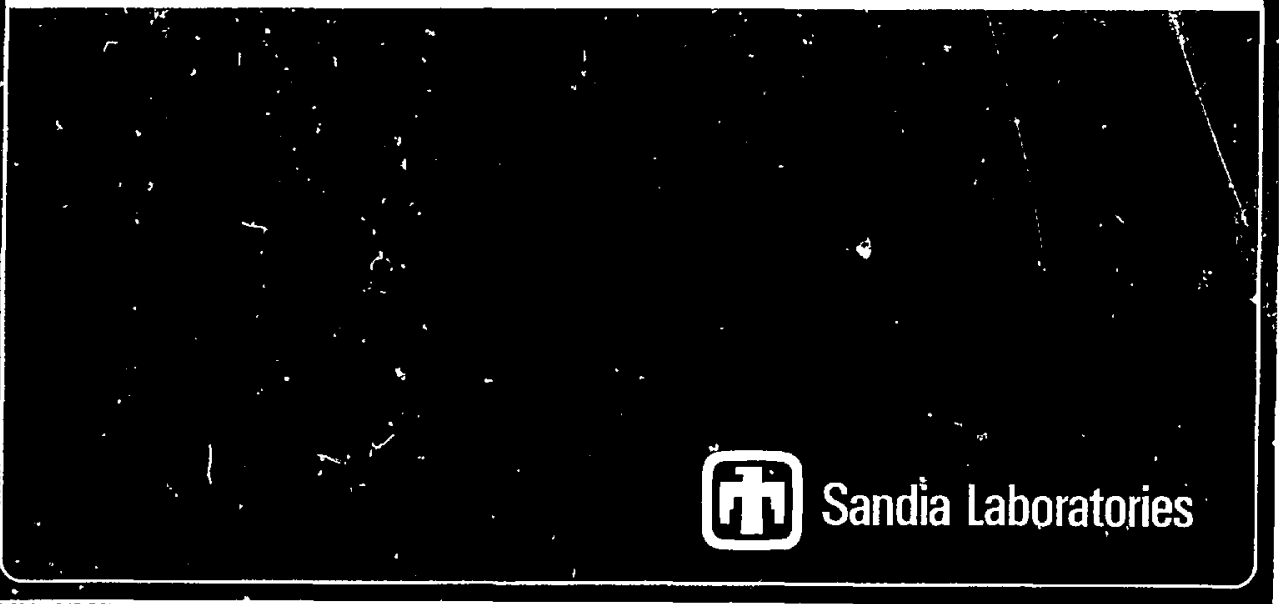

SF $29000(7.73)$

\section{MASTER}


SAND7B-0336

Unlimited Release

Printed March 1078

THE THOMSON PARABOLA ION ANALYZER

Michael A. Guginow

Maurice M. Dillon

Plasma and Laser Physics Division 5215

Grant J. Lockwood

Laurence E. Ruggles

Beam Source Application Diviston 5232

Sandia Laboratorles

Albuquerque, NM 87185

\section{ABSTRACT}

A Thomeon parabola ion analyzer is calbrated for lon energy and Ionic charge to mase ratio determination. Characteristic of this device which influence its operation are discussed.
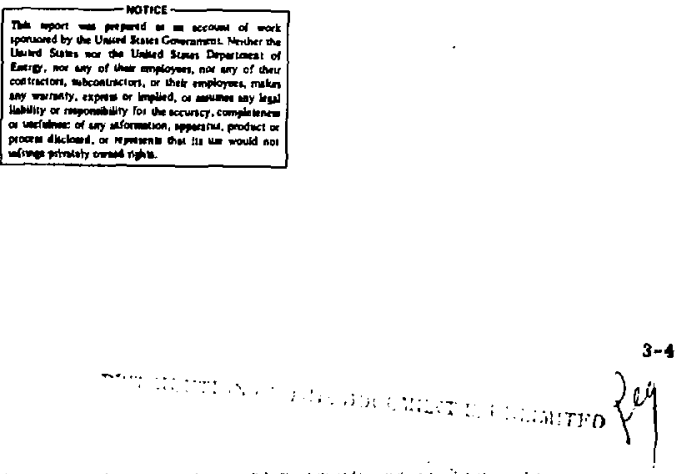


\section{CONTENTS}

Perpe

Introduction

7

Theary of Operation

7

Apperatus and Procedure

9

Results and Discusalion

Refererces 
This report describen the oporetion and calibration of a Thancon-paraboln lon analycer. This intrument is capable of meanuring the lonis charge atater presnot in a pleme. It also exhlbits enercy diparaion which in principle makoe it poselble to determlne the dintribution a

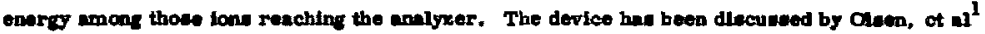

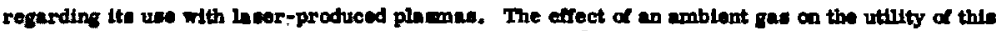

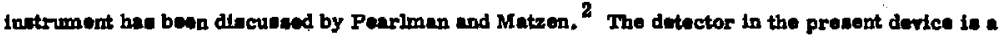

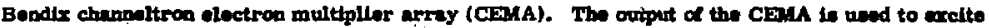
a phouphor, the output of which in then recorded on Elm. The output of the CEMA-phomphor doee not resdily allow for culbration to ancertain the abaolute (or relative) number of particlos impingIng upon It. Consequently, with a CEMA one must be content to determine charge atated and certaln aspects of the enercy of the enmpled plesme. Absolute monerremente of the len meray dietribution can be made by uthizine an approprinte detector. There are a veriaty of plame lon datector avallable; we mention one of them because of certain aimilarities to the Thomacn paraboln in if

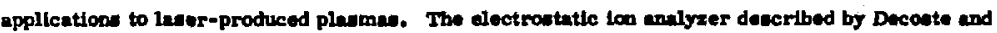
Rjpin ${ }^{4}$ and by Lockwood ${ }^{5}$ bus the adventage over the prevent ingtrameat of fivins the time-of-

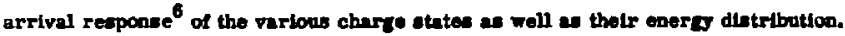

\section{Theors of Operatlon}

A achematic representation of the derlce to shown in Figra 1.

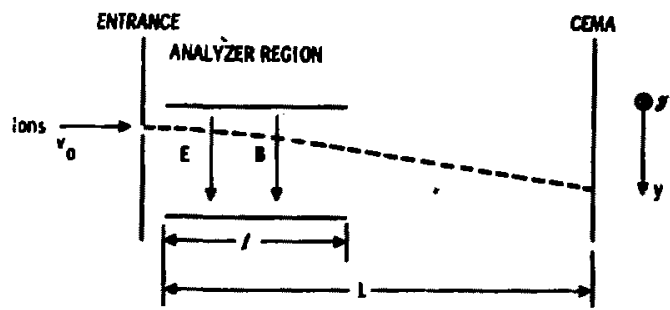

$\Delta y=\frac{27 q L}{M v_{0}^{2}}\left\{1-\frac{l}{2 L}\right\}$

$$
\left.4 y-\frac{24}{2 y} \mid 1-\frac{1}{2 L}\right\}
$$

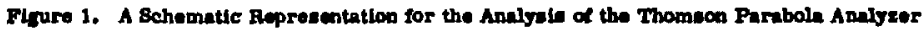


The equations of motion governing an incoming ion of charge Z, atomic mass A, and velocity vore:

$$
\begin{aligned}
& \ddot{\mathbf{x}}=-\boldsymbol{\omega}_{\mathbf{H}} \mathbf{v}_{\boldsymbol{X}} \\
& \ddot{\mathbf{y}}=\frac{\mathbf{Z}_{\mathbf{E}}}{\mathbf{M}} \boldsymbol{} \\
& \ddot{\boldsymbol{y}}=\boldsymbol{\omega}_{\mathbf{H}}^{\mathbf{v}} \mathbf{x}
\end{aligned}
$$

where $\omega_{H}=\mathrm{ZeB} / \mathrm{M}, \mathrm{M}\left(\mathrm{M}=\mathrm{Am} \mathrm{m}_{\mathrm{o}}\right.$, where $\mathrm{m}_{\mathrm{o}}$ is the proton mass) is the atomic mags, e is the electronic charge, $B$ and to are the applied magnetic and electric fields respectively. These equations are enally solved to find the trefectory of the particle in the analyzer region (length 2 ). Upon leaving the analyzer reglon, the particle Is in free fight and impinges upon the CEMA where it is detected. The locus of Ions with a constant charge-to-mass ratio for various energies ls given in the equations in Figure 1. The pattern degeribed ls a parabola in the y-g plane given by

$$
(\Delta y)\left(\frac{1 L_{B}{ }^{2} e}{m_{0} g}\right)\left(\frac{z}{A}\right)=(\Delta y)^{2}
$$

The coordinate ayetem and unite along the ads for the ingtumment used in this work are ghown in Flgure 2 (axes labeled according to Eqs. 1 and 2).

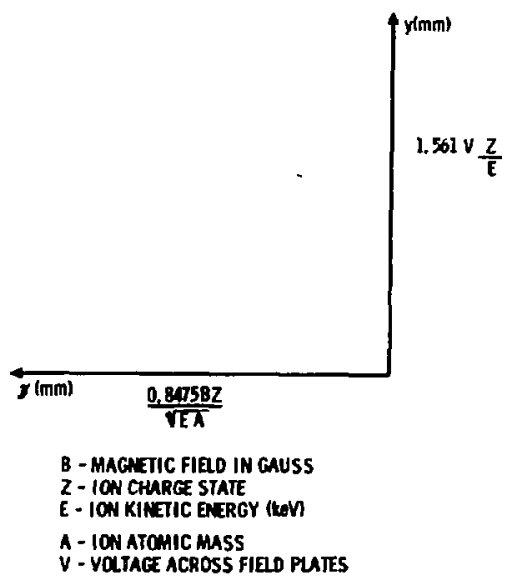

Figure 2. The Coordinate Syatem Uaed for Analyste of the Ion Traces Obeerved at the Anslyzer Bxit Face 
For a particular parabola (given $Z / A$ ) those ions farthest from the origin correspond to lower entrance energles than those cloger to the origin. The above equatlons agsume $\omega_{\mathrm{H}} l / v_{0} \ll 1$ and are correct to first order. The velocity in the $x$-direction to flrot order does not change as the particle traverses the analyzer region. The error involved in not going to higher orders is less than 1 percent for typical laser-plasma conditions.

The above is derlved for single particle behavior. The effects of fringing fields and apace charge on the partlcle trajectorles will be dealt within this report.

Apparatus and Procedure

The analyzer to be callbrated lo shown gchematically in Figure 1 where $\ell=150 \mathrm{~mm}$, $L=333 \mathrm{~mm}$ and the plate opacing was $12.4 \mathrm{~mm}$. Note that the electric field plateg were rande 's goft iron and served as the $r^{-}$-netic pole pieces for the magnetic fleld. The fleld was obtained by placing permanent magnets on both sides of the analyzer (outgide the vacuum housing) at the position of the internal pole pieces, and was varied by changing the apacing between the externally applied magnets and the pole pieces by the use of aluminum Bpacers.

The Sandia Laboratorieg $100 \mathrm{kV}$ Ion accelerator was used in this atudy. The Iong were produced in an $r f$ lon source using $\mathrm{H}_{2}$, Ne, and Ar gas. The source provided long frcm charge 1 to 3 depending on the gae ueed. The accelerator delivered a beam of magnetlcelly analyzed long (having an energy apread of leas than $34 \mathrm{oV}$ ) to the analyzer. The beam energy was determined to within a 1,0\% accuracy by meaguring the terminal potentlal with a voltage divider and correctIng for lon-source potentials. Due to charge transfer from collisions with background gas molecules in the accelerator between the ion beam analyzing magnet and che Thomson pariboln analyzer, the Incident beam contained a small fraction of lons of lower charge state than those selected by the anolyzing magnet. The small neutral component produced an image on the recording film corresponding to zero deflection, This imago was used as the reference from which the deflections were measured. In the cases of selected doubly and triply charged loris, the lower charge states allow for slmultaneous measurement of the defection of various charge to mass ratio lons with a common velocity.

The following procedure was used in the calfibration. For each aelected charge-to-masa ratio lon beam at a given energy (1.e., velocity) the beam was pulged on for a time gufficlent to obtain a good fllm exposure. This was repeated as the electric ind magnetic flelds applled to the anglyzer were varied in discrete steps. The electric fleld was varled by chnnging the voltage applied in the electric field plates. The magnetic field was varied by use of the aluminum opacers previously mentioned. 
During the course of this work, measurements were made for ions of various charge-tomass ratiog from 1:1 to 1:40. The velocity range covered was from $2.17 \times 10^{7} \mathrm{~cm} / \mathrm{s}$ to $4.38 \times$ $10^{8} \mathrm{~cm} / 5$. Table 1 lists the velocitieg of tlie various charge-to-mass ratios of the fon specieg used.

\section{TABLE !}

Charge-To-Mass Ratio and Velocity of fons Used in Calibration

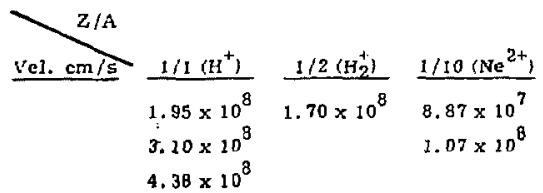

$$
3 / 40\left(\mathrm{Ar}^{3+}\right)
$$

$1 / 20\left(\mathrm{Ne}^{+} \mathrm{Ar}^{2+}\right)$

$2.17 \times 10^{7}$

$3.99 \times 10^{7}$

4. $38 \times 10^{7}$

6. $20 \times 10^{7}$

$7.58 \times 10^{7}$

$8.74 \times 10^{7}$

$8.77 \times 10^{7}$

$9.78 \times 10^{7}$

$1.07 \times 10^{\mathrm{B}}$
$1 / 40\left(\mathrm{Ar}^{+}\right)$

$2.19 \times 10^{7}$

$4.90 \times 10^{7}$

$6.92 \times 10^{7}$

7
$0^{7}$


The magnetic ficld was kept at zero and the electric field was varicd by chantring the plate voitage in six $80-V$ stejs from 0 to 480 volts. The voltages listed a re the total voltage differences between the plates. This was accomplished by applying $-\{1 / 2) \mathrm{V}$ to one plate and $+(1 / 2) \mathrm{V}$ to the other plate. The results arc a series of seven exposurea along the electric (y) axis. The loweet (brightesi) spot defines the origin and occurs in the case of zero electric and magnetic ficids. This is because the beam strikes this location each time it is pulsed on. Each of the other six exposurea appear to consist of two spots. We believe that this effect is caused by a surface charge on the CEMA face. For CFMA voltages less than $-1000 \mathrm{~V}$ only a single spot accurred. Figure 4 showa the results for incident beams of $1.70 \times 10^{8} \mathrm{~cm} / \mathrm{g}(30.14 \mathrm{keV}) \mathrm{H}_{2}^{+}, 2.17 \times 10^{7} \mathrm{~cm} / \mathrm{s}(4.94 \mathrm{keV}) \mathrm{Ne}^{+}$ and $2.18 \times 10^{2} \mathrm{~cm} / \mathrm{s}(10.02 \mathrm{keV}) \mathrm{Ar}^{+}$respectively.
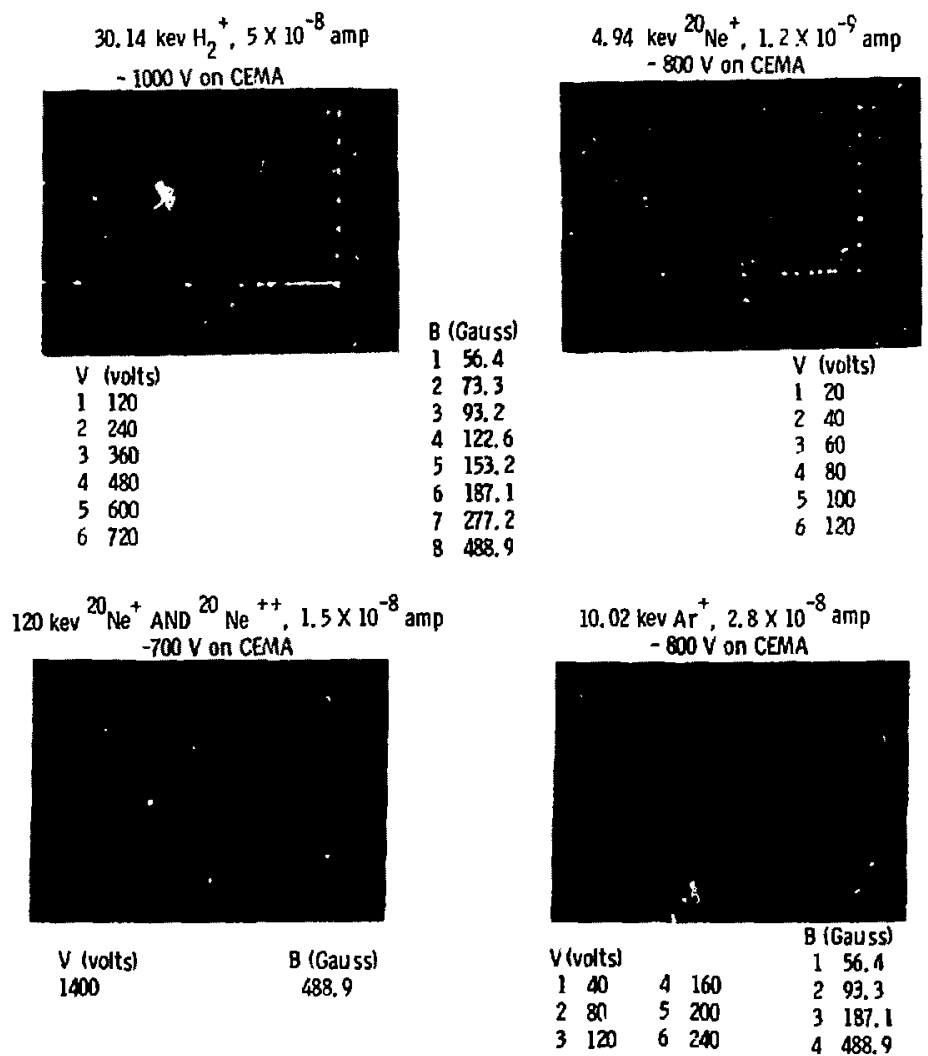

Figure 4, The Calibration Output for Various Ions and Energieg 
In thege cases, the electric field was first varied in gteps with a zoro magnetic fleld; then the magnetic field was varied in steps with a zero electric field. As in Figure 3 , the deflections due to the varied electric field appear as spots along the $y$ axis. The deflections due to the varied

- magnetic field appear as epots along the $y$ axis. Also shown in Figure 4 are the regulte for an Incident $\mathrm{Ne}^{2+}$ Leam with a velocity of $1.07 \times 10^{8} \mathrm{~cm} / \mathrm{\theta}(120 \mathrm{keV}$. As explained earlier, due to charge transfer there was alse a small beam of $\mathrm{Ne}^{+}$at $1.07 \times 10^{8} \mathrm{~cm} / \mathrm{s}$. Thus with zero magnetic field and $1400 \mathrm{~V}$ on the electric fleld plates, two deflected apots appear along the $y$ axis. The upper spot is due to the $\mathrm{Ne}^{+2}$ whlle the lower spot is due to the $\mathrm{Ne}^{+1}$. Then with the electric fleld at zero. a magnetic field was applled reaulting in the two spots along the $r$ axis. Finally both fields were applied at the same time giving rise to the two off-axis spots.

When the measured deflectiona due to the electric field are compared with those predicted by Eq. 1 the average difference is 1,98 percent for enorgies of $40 \mathrm{keV}$ an higher. However. the difference increases as the energy is lowered, reaching a value of 8.12 percut at $4.94 \mathrm{keV}$. It is believed that this is caused mainiy by the electric fleld due to the negative voltage applied to the front of the CEMA.

A mapping of the magnotic field with a gauge metes. Indicated an average variation of appraximately 3 percent and e peak of 11 percent. Frodn the met wured megnetic defioctlons with the varlous apacers, effective magnetlc flelda can be inferred. The ge are shovn in Table II.

TABJE II

Effective Magnetic Fleids Lletermined From Callbration

\begin{tabular}{ccc}
$\begin{array}{c}\text { Spacer } \\
\text { Number }\end{array}$ & $\begin{array}{c}\text { Spacer } \\
\text { Thickness } \\
(\mathrm{cm})\end{array}$ & $\begin{array}{c}\text { Magnetic Field } \\
\text { (Gausg) }\end{array}$ \\
\cline { 2 - 3 } 1 & 3.810 & $66.4( \pm 5.4 \%)$ \\
2 & 3.175 & $73.3( \pm 3.9 \%)$ \\
3 & 2.540 & $93.2( \pm 4.0 \%)$ \\
4 & 1.905 & $122.6( \pm 5.6 \%)$ \\
5 & 1.587 & $153.2( \pm 2.0 \%)$ \\
6 & 1.270 & $187.1( \pm 2.9 \%)$ \\
7 & 0.635 & $277.2( \pm 5.8 \%)$ \\
8 & 0 & $488 . \theta( \pm 2.8 \%)$
\end{tabular}

The average precision is taken to be 4 percent. Using the results of these callbrations, relations can be obtained among dellections in the electric and mggnetic fleld to the charge-to-mase ratio and the velocity of the incident lons. Using Eqs. 1 and 2 the following occurs; 


$$
\frac{Z}{A}=2.17 \frac{(\Delta,)^{2}}{\Delta y}\left(\frac{V}{b^{2}}\right)
$$

and

$$
v_{0}=8.06 \times 10^{7}\left(\frac{i}{2 y}\right)\left(\frac{y}{15}\right) \mathrm{cm} / \mathrm{sec}
$$

where $Z / A$ is the icnic charge per arn amoze specifically 2 is the charge state of the ion), $\Delta y$ and $\Delta y$ are in $\mathrm{mm}, \mathrm{Y}$ is in volts, and $\mathrm{B}$ is in Gauss. $\mathrm{B}$ is the effective magnetic field and \pm 4 percent precision is associated with it. Wo ascribe an average precision of \pm 3 perr 4 th to an effective deflection plate voltage (aside (rom the systematic errors previously noted). Consequently, the charge-tomass ratio (Eq. 7) can be determined with an uncertainty of \pm 11 percent, while the velocity can be determined to vithin \pm 7 percent. Many laser-plasma experiments deal with a specific target material and hence $A$ is unambiguously known. In important quantity is $E / Z$ where $E$ is the kinetic energy of the $z^{\text {th }}$ charge state entering tisc analyzer region. In this ease ffrom figure 2 ),

$$
\frac{E}{Z}=1,561\left(\frac{V}{d y}\right) \mathrm{keV}
$$

The energy of the various charge states obstrved can be determined is within \pm 3 percent.

The Thomson parabola ion analyzer has been calibrated for use with laser experimants to study expanding plasmas produced by laser interaction with a solid target. In this case the prineipal mass component (A) of the plasma is known; thus, one can obtain lonlc charge and energy information. Figure 5 is a typical trace from an experimen: using an Al target and a $50 \mathrm{ps}, 900 \mathrm{~mJ}$, $1.06 \mu$ laser.

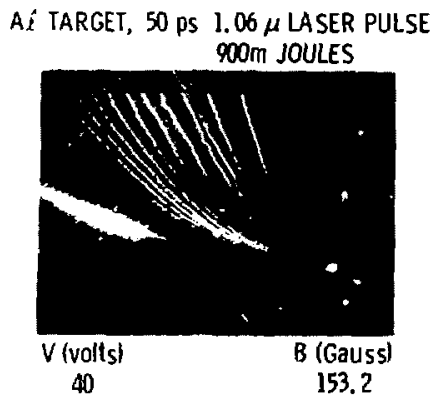

Figure 5. $\Lambda$ Tspical Thomson Parabola Analyzer Output for an Expanding Af Plasma Produced with a $50 \mathrm{ps}$, $900 \mathrm{mt}^{\mathrm{T}}$. $1.60 \mu \mathrm{Laser}$ 
Various stages of ioniation of the Al are observed $(Z=1$ through 11$)$ as well as Impurlties. The mogt notable impurity is $\mathrm{H}^{+}$, the brightest trace in the left-hand comer. The absence of the traces: towards the origln is indicative of an upper energy cutoff th the expanding plas ma.

\section{Aeferences}

1. J. N. Olaen, G. W. Kugw日, E. D. Joneg, J. A. P., 44, 2276, 1873.

2. J. Pearlman and M. K, Matzen, paper 10H4, 1 bth Arnual Meeting of the Diviston of Plasma Physics, 1877

3. F. Young and G. H. McCall, paper 5H9, lbid, 1 gth Annual Meeting of the Dlviglon of Plama Physics; 1977.

4. R. DeCoste and B, H. Ripln, Rev, Scl. Instru., 48, 232, 1977.

5. G. J. Lockwuod, Sandia Rebearch Report, SC-RR-70-583, 1870.

6. E. D. Jones auggestef privately efrce 1976 that a traming camera be utllized to look at the CEMA response as a function of time during plesma expansion. 